Kumawula, Vol. 3, No.3, Desember 2020, Hal 507 - 514

DOI: https://doi.org/10.24198/kumawula.v3i3.29993

ISSN 2620-844X (online)

Tersedia online di http://jurnal.unpad.ac.id/kumawula/index

\title{
BERAKSI CEGAH PENYAKIT TIDAK MENULAR DI RW 2 KELURAHAN JAYAWARAS TAROGONG KIDUL GARUT
}

\author{
Udin Rosidin $^{1}$, Witdiawati ${ }^{2}$, Umar Sumarna ${ }^{3}$ \\ ${ }^{1}$ Fakultas Keperawatan, Universitas Padjadjaran \\ ${ }^{2}$ Fakultas Keperawatan, Universitas Padjadjaran \\ ${ }^{3}$ Fakultas Keperawatan, Universitas Padjadjaran \\ *Korespondensi : udin.rosidin@unpad.ac.id
}

\begin{abstract}
ABSTRAK
Kegiatan PPM ini dilatarbelakangi dengan tingginya penyakit tidak menular seperti hipertensi dan diabetes melitus (DM). Keadaan seperti ini akibat adanya pergeseran pola penyakit, dari penyakit menular ke penyakit tidak menular. Konsep transisi epidemiologi tersebut menggambarkan adanya kecenderungan dominasi penyakit degenaritif yang sangat ditentukan oleh perilaku masyarakat. Perilaku masyarakat yang sangat tepat untuk mengatasi penyakit degeneratif ini adalah dengan melaksanakan PHBS. Dalam kegiatan survey yang dilaksanakan di RW 02 Kelurahan Jayawaras oleh mahasiswa profesi menunjukan banyak masyarakat yang menderita penyakit hipertensi dan diabetes melitus. Tujuan dalam kegiatan PPM ini diharapkan adanya gerakan masyarakat untuk mencegah penyakit tidak menular (PTM) khususnya penyakit hipertensi dan diabetes melitus. Metoda pelaksanaan PPM yang dilakukan diawali dengan persiapan sosial dengan melakukan pendekatan pada pihak terkait, baik lintas program maupun lintas sektoral. Kemudian melakukan serangkaian kegiatan upaya pencegahan PTM dengan tema BERAKSI CEGAH PTM. Kegiatan ini disepakati oleh seluruh masyarakat melalui musyawarah masyarakat kelurahan. Namun saat kegiatan sedang berjalan terjadi beberapa perubahan strategi pelaksanaan karena adanya pandemi Covid 19. Hasil kegiatan tidak seluruhnya bisa diikuti seluruh masyarakat karena metoda yang digunakan sebagian menggunakan metode daring. Kegiatan senam hipertensi dan pemeriksaan kesehatan diikuti oleh sebagian warga masyarakat sedangkan pendidikan kesehatan diikuti oleh ketua RT, RW dan kader kesehatan. Hasil pengabdian ini diharapkan akan menjadi kebiasaan yang baik dari seluruh masyarakat terutama dalam menjalankan perilaku hidup bersih dan sehat sehingga dapat tercegah dari penyakit tidak menular.
\end{abstract}

Kata Kunci : Beraksi, Cegah, Penyakit Tidak Menular

\begin{abstract}
This PPM activity is motivated by the high rate of non-communicable diseases such as hypertension and diabetes mellitus (DM). This situation is due to a shift in disease patterns, from infectious to non-communicable diseases. The concept of epidemiological transition illustrates the tendency to dominate degenerative diseases which is largely determined by people's behavior. Community behavior that is very appropriate to overcome this degenerative disease is to implement PHBS. In the survey activities carried out at RW 02 Jayawaras Village by professional students, it shows that many people suffer from hypertension and diabetes mellitus. The purpose of this PPM activity is to hopefully have a community movement to prevent non-communicable diseases (PTM), especially hypertension and diabetes mellitus. The method of implementing PPM begins with social preparation by approaching related parties, both cross-program and cross-sectoral. Then carry out a series of activities to prevent PTM with the theme of ACTION TO PREVENT PTM. This activity was agreed upon by the entire community through community meetings in the sub-district. However, while the activity was underway, there were several changes to the implementation strategy due to the COVID-19 Pandemic. The results of the activities were not entirely accessible to the whole community because some of the methods used were online. Some members of the community participated in the hypertension gymnastics activity while health education was attended by heads of RT, RW and health cadres. It is hoped that the results of this service will become a good habit for the whole community, especially in carrying out a clean and healthy lifestyle so that it can be prevented from noncommunicable diseases.
\end{abstract}

Keywords: Take Action, Prevent, Non-Communicable Disease 


\section{PENDAHULUAN}

Ilmu pengetahuan dan teknologi saat ini sedang pesat perkembangannya di seluruh dunia. Pesatnya perkembangan teknologi bidang kesehatan sangat berdampak pada peningkatan hasil pembangunan dan produktifitas penduduk. Perkembangan tersebut berdampak pula pada perubahan pola penyakit, penurunan angka kematian akibat sakit dan meningkatnya usia harapan hidup. Perubahan pola penyakit yang dimaksud adalah terjadi pergeseran dari penyakit menular ke penyakit tidak menular. Beberapa tahun terakhir terjadi pergeseran pola penyakit dimana penyakit menular tidak lagi menjadi penyakit terbanyak dalam pelayanan kesehatan, melainkan penyakit tidak menular (PTM) yang memiliki proporsi utama yaitu 57\% dari total kasus (Kemenkes 2018b).

PTM merupakan penyebab utama kematian secara global. Data WHO tahun 2010 menunjukkan bahwa 63\% penyebab kematian di seluruh dunia disebabkan oleh PTM (Yarmaliza and Zakiyuddin 2019). World Health Organization (WHO) memprediksi, pada tahun 2020 Penyakit Tidak Menular (PTM) menjadi penyebab dari 73 \% kematian dan $60 \%$ terdiagnosa di seluruh dunia. Salah satu PTM yang menjadi masalah kesehatan serius saat ini adalah hipertensi (Wahidin et al. 2019). Hipertensi merupakan faktor resiko utama terjadinya penyakit kardiovaskuler yang merupakan penyebab utama kematian di seluruh dunia. Hipertensi yaitu keadaan dimana terjadinya peningkatan tekanan darah secara terus menerus sehingga melebihi batas normal. Hipertensi sering disebut sebagai Silent Killer, karena hipertensi merupakan penyakit yang mematikan tanpa disertai adanya gejala terlebih dahulu. Hipertensi juga merupakan penyakit yang sering dijumpai di masyarakat dengan jumlah penderita yang terus meningkat setiap tahunnya (Situmorang 2015). Prevalensi hipertensi diprediksikan akan terus meningkat tajam pada tahun 2025 nanti dengan sekitar $29 \%$ orang dewasa menderita hipertensi di seluruh dunia.
Hipertensi mengakibatkan kematian sekitar 8 juta orang setiap tahun, 1,5 juta kematian terjadi di Asia Tenggara, yang sepertiga populasinya menderita hipertensi (Hakim and Tazkiah 2019).

Di Indonesia hipertensi menjadi masalah kesehatan masyarakat yang semakin tinggi dan berat. Berdasarkan Riset Kesehatan Dasar (Kemenkes 2013) prevalensi hipertensi pada penduduk umur lebih dari 18 tahun ke atas di Indonesia adalah sebesar 25,8 \%. Prevalensi Penyakit Hipertensi terus mengalami kenaikan Riskesdas tahun 2018 menunjukkan berdasarkan pengukuran tekanan darah, hipertensi naik dari 25,8\% menjadi 34,1\% (Kemenkes 2018a). Provinsi Kalimantan Selatan, Kalimantan Timur, dan Jawa Barat merupakan provinsi yang mempunyai prevalensi hipertensi lebih tinggi dari angka nasional. Prevalensi hipertensi di Jawa Barat cukup besar yaitu 29,4 \% (Kemenkes 2013). Data Dinas Kesehatan Kabupaten Garut, didapatkan bahwa penderita hipertensi Di Kabupaten Garut sebanyak 70.540 orang dengan 24.832 laki - laki dan 45.708 perempuan (Garut 2013) . Hipertensi meningkat sejalan dengan perubahan gaya hidup tidak sehat (Cahyono 2008). Beberapa penelitian menunjukkan bahwa hipertensi disebabkan oleh berbagai faktor diantaranya pola konsumsi natrium, obesitas, merokok, kebiasaan olahraga/aktivitas fisik, Stress dan alkohol (Hakim and Tazkiah 2019). Prevalensi merokok pada remaja (10-18 tahun) terus meningkat, yaitu 7,2\% (Kemenkes 2013) menjadi 9,1\% (Kemenkes 2018a). Data proporsi konsumsi minuman beralkohol pun meningkat dari 3\% menjadi 3,3\%. Demikian juga proporsi aktivitas fisik kurang juga naik dari 26,1\% menjadi $33,5 \%$. Hal lainnya adalah proporsi konsumsi buah dan sayur kurang pada penduduk 5 tahun terakhir masih sangat bermasalah yaitu sebesar 95,5\%. (Kemenkes 2018b).

Penanganan hipertensi dilakukan melalui perbaikan pola hidup seperti mengkonsumsi makanan yang lebih banyak buah, sayur dan kadar lemak yang rendah, melakukan aktivitas fisik seperti olahraga teratur, tidak mengkonsumsi alkohol, dan berhenti merokok 
total (Cahyono 2008). Menteri Kesehatan Republik Indonesia membuat Pedoman Pembinaan Perilaku Hidup Bersih dan Sehat yang diatur dalam Peraturan Menteri Kesehatan Republik Indonesia Nomor : 2269/MENKES/PER/XI/2011 yang mengatur upaya peningkatan perilaku hidup bersih dan sehat atau disingkat PHBS untuk menurunkan prevalensi penyakit tidak menular, namun pada kenyataannya di Jawa Barat PHBS masih jauh dari capaian nasional (Rosidin and Suhendar 2018). Rumah tangga yang sudah mampu menerapkan perilaku hidup bersih dan sehat (PHBS) di Jawa Barat sebanyak 51,40 \% berada pada posisi 12 dari 33 provinsi di Indonesia sedangkan capaian nasional menunjukkan sebesar 56,58\% (Rosidin, Sumarna 2019). Gerakan Perilaku Hidup Bersih dan Sehat merupakan ujung tombak untuk pembangunan kesehatan, sehingga semua tatanan rumah tangga harus dapat melaksanakan PHBS. Salah satu upaya untuk memberdayakan anggota rumah tangga agar tahu, mau dan mampu mempraktikkan perilaku hidup bersih dan sehat serta berperan aktif dalam gerakan kesehatan di masyarakat dengan mengadakan suatu Program PHBS di Rumah Tangga. Perilaku hidup bersih dan sehat seseorang sangat berkaitan dengan meningkatkan kesehatan individu, keluarga, masyarakat dan lingkungannya (Umaroh, Hanggara, dan Choiri 2016).

Rumah Tangga Ber-PHBS didapatkan dari rumah tangga yang seluruh anggotanya berperilaku hidup bersih dan sehat. Dimana rumah tangga sudah menerapkan 10 indikator PHBS Rumah tangga yaitu, persalinan ditolong oleh tenaga kesehatan, memberi bayi ASI eksklusif, menimbang balita setiap bulan, menggunakan air bersih,cuci tangan dengan air bersih dan sabun, pengelolaan air minum dan makan di rumah tangga, menggunakan jamban sehat (Stop Buang Air Besar Sembarangan/Stop BABS), pengelolaan limbah cair di rumah tangga, membuang sampah di tempat sampah, memberantas jentik nyamuk, khususnya dalam mengatasi PTM keluarga harus mampu menerapkan indikator PHBS makan buah dan sayur setiap hari, melakukan aktivitas fisik setiap hari, serta tidak merokok (Kemenkes 2011).

Berdasarkan hasil pengkajian yang dilakukan mahasiswa profesi di RW 02 Kelurahan Jayawaras terdapat dua penyakit tidak menular (PTM) tertinggi yang ditemukan yaitu hipertensi berjumlah 37 orang $(9,6 \%)$ dan diabetes melitus berjumlah 5 orang (1.5\%). Diketahui bahwa masyarakat yang memiliki tekanan darah tinggi grade I sebanyak 36 orang $(10,8 \%)$ dan grade II sebanyak 1 orang (0,3\%), diketahui bahwa 5 diantaranya sudah mengalami komplikasi lain yaitu jantung dan stroke. Tingginya PTM ini juga didukung dengan hasil pengkajian yang menunjukan mayoritas warga memiliki kebiasaan konsumsi makanan asin sebanyak 88 keluarga dari 101 keluarga (87,1\%), kebiasaan ngemil (90.1\%), minum kopi $(83,2 \%)$, merokok $(75,2 \%)$, dan tidak olahraga minimal 2x/minggu $(60,4 \%)$. Berdasarkan fenomena tersebut diperlukan adanya gerakan hidup sehat untuk mencegah PTM dengan pemahaman yang benar tentang penyakit Hipertensi dan DM. Peningkatan pemahaman tersebut harus diawali dengan peningkatan pengetahuan, sikap dan motivasi masyarakat dalam melakukan pencegahan PTM. Maka disepakatilah program Beraksi Cegah PTM (Bersama Masyarakat Siap Cegah Penyakit Tidak Menular) di RW 02 Kelurahan Jayawaras.

\section{METODE}

Sebelum kegiatan PPM dilaksanakan Tim PPM terlebih dahulu mengadakan pertemuan dengan Kepala Puskesmas Haurpanggung dan Kepala Kelurahan Jayawaras. Kemudian penulis dan mahasiswa melakukan survey untuk mengetahui permasalahan kesehatan yang sedang terjadi. Hasil survey mendapatkan bahwa PTM merupakan permasalahan yang banyak dirasakan oleh masyarakat. Permasalahan tersebut kemudian dibahas dalam musyawarah masyarakat kelurahan. Peserta musyawarah terdiri dari para kader kesehatan di RW 2, perwakilan Puskesmas Haurpanggung, perwakilan kelurahan Jayawaras, dosen pelaksana PPM dan 
mahasiswa pelaksana survey. Musyawarah menyepakati adanya kegiatan pengabdian pada masyarakat untuk mengatasi permasalahan yang ditemukan yaitu program yang disebut Beraksi Cegah PTM. Kegiatan pengabdian diawali dengan persiapan sosial yang bertujuan untuk membangun komitmen dari semua pihak yang terkait seperti Kepala Puskesmas Haurpanggung, Kepala Kelurahan Jayawaras, Ketua RW 2 dan kader kesehatan. Setelah program disepakati maka dilaksanakan beberapa kegiatan bersama masyarakat berupa senam bersama, pemeriksaan tekanan darah dan penyelenggaraan pendidikan kesehatan. Kegiatan pengabdian pada mulanya dilaksanakan secara luring kemudian dilanjutkan secara daring. Kegiatan akhir dari PPM ini adalah melakukan evaluasi dan melaporkan hasil kegiatan kepada Kepala Kelurahan Jayawaras, Kepala Puskesmas Haurpanggung, kader kesehatan dan tokoh masyarakat.

\section{HASIL DAN PEMBAHASAN}

Strategi pelaksanaan kegiatan diawali dengan kolaborasi aktif bersama masyarakat, para kader, tokoh masyarakat, kelurahan dan pihak Puskesmas. Kolaborasi dilaksanakan melalui musyawarah masyarakat dan unsur yang terkait. Kegiatan musyawarah dilaksanakan pada tanggal 11 Maret 2020. Saat ini belum ada himbauan untuk melakukan pembatasan sosial sehingga musyawarah bisa dilaksanakan secara langsung di masyarakat. Thema kegiatan yang disepakati adalah beraksi cegah PTM dengan kegiatan berupa ; 1) Melaksanakan kegiatan senam hipertensi, sebagai upaya pemberdayaan masyarakat, 2) Melaksanakan kegiatan pemeriksaan kesehatan (tekanan darah dan gula darah) sebagai upaya pemantauan kondisi kesehatan masyarakat secara rutin. dan 3) Melaksanakan kegiatan pendidikan kesehatan tentang penyakit tidak menular yaitu hipertensi dan DM. Kegiatan tersebut didasarkan pada harapan bahwa setelah dilaksanakan program tersebut akan terjadi sebuah dinamika didalam masyarakat menuju perilaku hidup bersih dan sehat, khususnya dalam upaya untuk mencegah penyakit hipertensi dan diabetes melitus. Penyakitpenyakit yang dikategorikan sebagai penyakit tidak menular umumnya perlu penanganan jangka panjang yang tidak hanya pada upaya medikasi. Penanganan PTM juga sangat diperlukan pada upaya bagaimana pengelolaan faktor pemberat seperti gaya hidup yang menunjukkan perilaku hidup bersih dan sehat. Sehingga program Beraksi Cegah PTM yang dilakukan hanya stimulant dan kemudian perlu dilaksanakan secara berkala melalui kolaborasi aktif antara masyarakat dan pihak terkait (Kartiningrum et al. 2017).

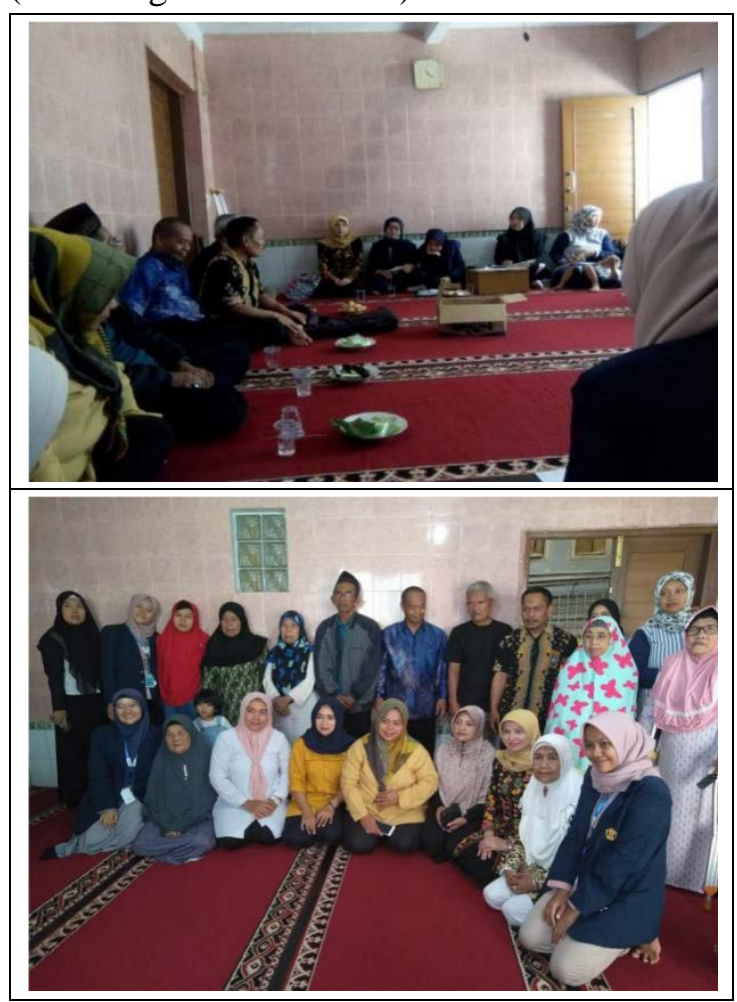

Gambar 1 Suasana musyarakat untuk membahas rencana kegiatan

Kegiatan awal yang disepakati dalam musyawarah adalah melaksanakan senam bersama seluruh masyarakat yaitu senam hipertensi dan senam cuci tangan. Kegiatan pertama ini dilaksanakan pada hari Minggu tanggal 15 Maret 2020 jam 08.00 sampai dengan 08.30. Senam bersama ini dilaksanakan di halaman kantor RW 02 yang diikuti oleh 20 orang secara langsung. Senam yang dilaksanakan secara langsung ini hanya dilakukan satu kali, selanjutnya senam dilaksanakan secara mandiri melalui koordinasi kader penanggung jawab senam. Kader penanggung jawab senam dilatih terlebih 
dahulu sehingga bisa menjadi instruktur bagi anggota masyarakat lainnya. Tim PPM menyarankan kepada kader penanggung jawab senam untuk membagikan video senam hipertensi yang sudah diberikan sehingga masyarakat tetap bisa melakukan senam secara mandiri di rumah. Sebelum kegiatan mandiri dilakukan terlebih dahulu kader penanggung jawab dilatih melalui kegiatan pemberdayaan kader kesehatan sebagai instruktur senam. Kegiatan pemberdayaan kader kesehatan ini dilaksanakan pada tanggal 19 Maret 2020 dengan cara memberikan video senam hipertensi dan senam cuci tangan. Diharapkan dengan melatih salah seorang kader kesehatan sebagai penanggung jawab kegiatan dapat terus dilaksanakan.

Senam merupakan salah satu aktivitas latihan jasmani. Latihan fisik yang dilakukan secara teratur ini merupakan penatalaksanaan teknik nonfarmakologi. Salah satu indikator perilaku hidup sehat adalah melakukan akifitas fisik minimal 30 menit setiap hari (Departemen Kesehatan 2011). Senam yang dilakukan secara bersama merupakan strategi yang tepat untuk mencegah penyakit yang diakibatkan oleh perilaku yang tidak sehat. Dengan melaksanakan kegiatan bersama merupakan salah satu cara untuk memberdayakan masyarakat. Pemberdayaan masyarakat yaitu dengan cara mengikutsertakan kader kesehatan akan memotivasi masyarakat untuk terlibat dalam mengatasi masalah-masalah kesehatan yang ada di masyarakat (Setyatama 2012)

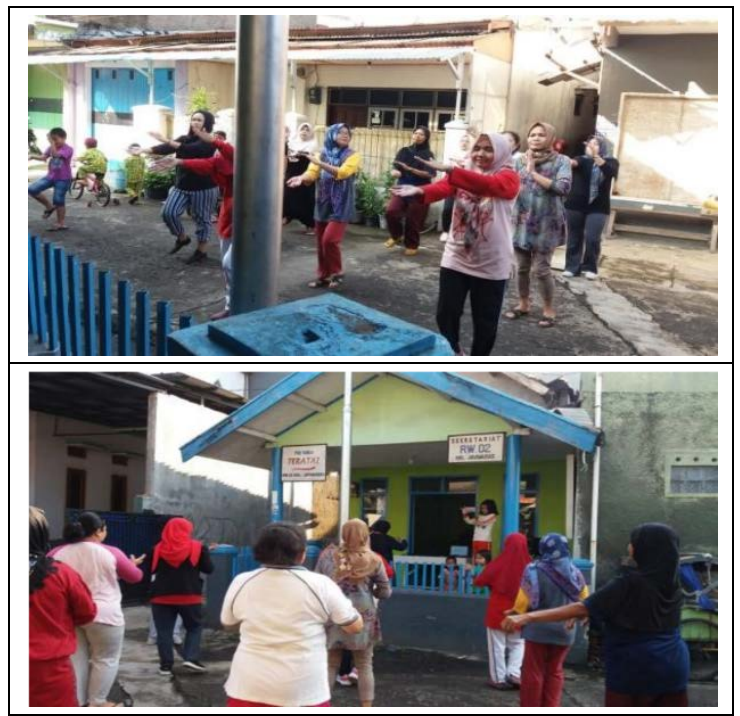

\section{Gambar 2 Pelaksanaan senam bersama masyarakar RW 02}

Setelah melakukan senam bersama kemudian dilaksanakan pemeriksaan kesehatan berupa pengukuran tekanan darah dan pemeriksaaan gula darah. Pemeriksaan kesehatan diikuti oleh 25 orang. Sebelum dilakukan pemeriksaan kesehatan terlebih dahulu masyarakat melakukan pendaftaran untuk mendata apakah memiliki resiko penyakit atau tidak. Bagi masyarakat yang tidak hadir dan memiliki resiko penyakit dilakukan kunjungan rumah / skrining untuk pemeriksaan tekanan darah atau pemeriksaan gula darah. Kegiatan pemeriksaan kesehatan merupakan upaya agar masyarakat mau melaksanakan hidup sehat. Menurut (Junita, Handayani, and Alfiah 2020) Gerakan masyarakat hidup sehat merupakan upaya untuk meningkatkan kesadaran, kemauan dan kemampuan bagi setiap orang untuk hidup sehat agar peningkatan derajat kesehatan masyarakat yang setinggi-tingginya dapat terwujud. Tujuan umum gerakan masyarakat hidup sehat, a) Perubahan gaya hidup lebih baik dan b) Meningkatnya peran masyarakat dalam memanfaatkan fasilitas kesehatan.

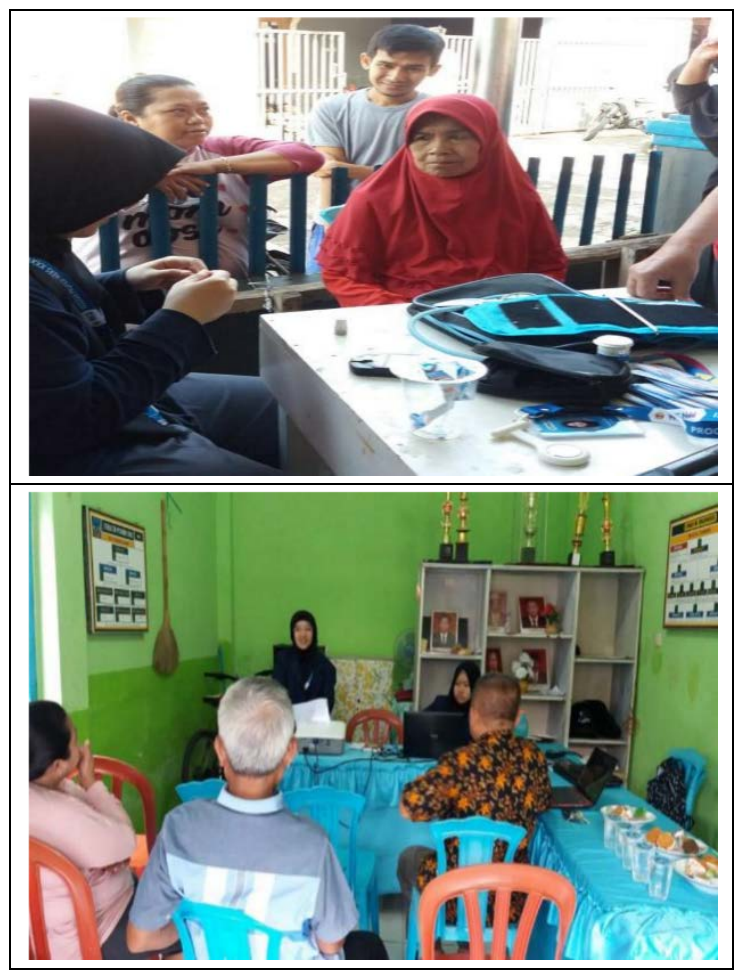

Gambar 3 Pelaksanaan Pemeriksaan

Kesehatan

Pemeriksaan kesehatan secara rutin merupakan upaya pencegahan penyakit 
hipertensi maupun penyakit diabetes melitus. Menerapkan gaya hidup yang sehat adalah dengan cara melakukan pemeriksaan kesehatan secara rutin. Menurut (Soenanto 2009) Pencegahan yang perlu dilakukan untuk mencegah hipertensi adalah menerapkan gaya hidup sehat. Demikian juga dengan penyakit diabetes melitus apabila gula darah terkontrol dengan rutin dapat mencegah terjadinya komplikasi seperti penyakit kardiovaskuler, gagal ginjal, kebutaan, amputasi, patah tulang, kelemahan dan depresi (Dahlan, Bustan, and Kurnaesih 2018).

Kegiatan terakhir yang dilaksanakan dalam program "Beraksi cegah PTM di RW 02 Desa Jayaraga” adalah melakukan kegiatan pendidikan kesehatan. Pendidikan kesehatan dilaksanakan pada masa awal pemberlakuan pembatasan sosial akibat pandemi covid 19 . Pendidikan kesehatan PTM (Hipertensi dan DM) dilaksanakan dengan strategi kulwap (kuliah melalui whatsapp) dengan membentuk grup whatsapp yang terdiri dari Tim PPM, RW, RT, kader dan masyarakat. Media yang digunakan yaitu video, rekaman suara (voice note) dan gambar. Pendidikan kesehatan PTM Diabetes Meilitus dilaksanakan pada tanggal 22 Maret 2020 pukul 11.00 sampai jam 14.00. Materi untuk PTM DM yaitu pengertian DM, faktor resiko DM, tanda gejala DM dan cara mengontrol gula darah normal. Pendidikan kesehatan PTM Hipertensi dilaksanakan sore harinya yaitu 14.30 sampai jam 17.30. Materi yang disampaikan yaitu : pengertian hipertensi, faktor risiko hipertensi, tanda gejala hipertensi, komplikasi hipertensi, penatalaksanaan hipertensi dan pencegahan hipertensi.

Pendidikan kesehatan yang dilakukan merupakan upaya peningkatan pengetahuan masyarakat agar dapat melakukan hidup sehat untuk mencegah penyakit tidak menular. Menurut (Notoatmodjo 2014) Pendidikan kesehatan merupakan salah satu upaya untuk meningkatkan pengetahuan. Walaupun pendidikan kesehatan dilakukan secara daring, tim berusaha mengkemas materi dalam bentuk media yang mudah dimengerti dan sangat manarik masyarakat. Materi dikemas menarik dalam bentuk video, poster dan leaflet yang dikirim melalui personal chart. Media pendidikan kesehatan yang menarik seperti vidio, poster dan leaflet akan menjadi perhatian masyarakat untuk melihat atau membacanya. Pembuatan media yang menarik akan lebih efektik untuk meningkatkan pengetahuan masyarakat tentang perilaku hidup bersih dan sehat (Sumarni, Rosidin, and Sumarna 2020).

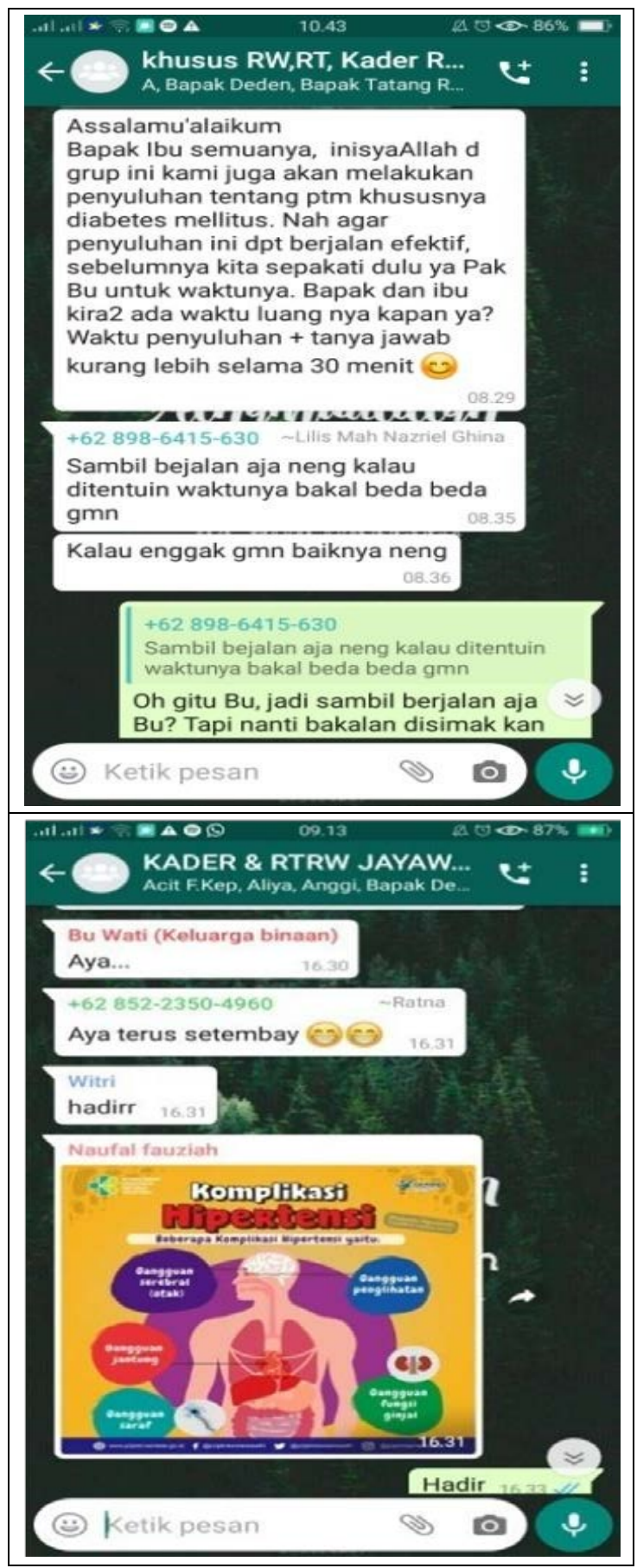

Gambar 4 Materi pendidikan kesehatan

Pendidikan kesehatan melalui personal chart ini diharapkan dapat menjadi bahan informasi kepada masyarakat untuk hidup sehat. Beraksi cegah PTM akan mudah dilaksanakan 
apabila masyarakat memiliki informasi yang baik tentang pencegahan PTM. Menurut (Notoatmodjo 2014), informasi merupakan faktor yang sangat penting dalam meningkatkan pengetahuan seseorang. Seseorang yang memiliki informasi akan memiliki pengetahuan yang luas dan bisa mengaplikasikan atau menerapkan pengetahuan yang telah diperoleh dibandingkan dengan seseorang yang belum mendapatkan informasi. Informasi bisa didapatkan dari beberapa sumber media atau salah satunya dengan pendidikan kesehatan. Pendidikan kesehatan merupakan suatu upaya untuk belajar seperti memberikan informasi dan pelatihan menggunakan media yang menarik (Efendi and Makhfudli 2010). Hal ini sejalan dengan hasil penelitian (Wahyuningsih and Astarani 2018) yang menyatakan bahwa pengetahuan dan sikap serta keterampilan kader kesehatan dapat ditingkatkan dengan melakukan pendidikan kesehatan.

\section{SIMPULAN}

\section{Program Beraksi Cegah PTM} merupakan pengembangan kegiatan untuk meningkatkan perilaku hidup bersih dan sehat dalam upaya meningkatkan kesadaran masyarakat terhadap Penyakit Tidak Menular. Kegiatan yang dilaksanakan berupa pemberdayaan masyarakat dengan kegiatan senam bersama, pemeriksaan kesehatan dan pendidikan kesehatan. Pada kegiatan ini masyarakat RW 02 Kelurahan Jayawaras Garut cukup antusias mengikuti rangkaian kegiatan tersebut. Meskipun dalam pelaksanaannya diperlukan beberapa perubahan strategi, namun informasi dapat tersampaikan melalui pemberdayaan kader RW 02. Diharapkan kegiatan Beraksi Cegah PTM ini dapat menjadi kegiatan rutin yang dilaksanakan di RW 02 Kelurahan Jayawaras sehingga masyarakat dapat melaksanakan perilaku hidup sehat. Dengan perilaku hidup sehat maka masyarakat akan dapat melakukan pencegahan PTM secara mandiri.

\section{UCAPAN TERIMA KASIH}

Ucapan terimakasih kepada Rektor Universitas Pajajaran, Dekan Fakultas Keperawatan Universitas Pajajaran, Camat Kecamatan Tarogong Kidul Garut, Kepala Puskesmas Haurpanggung Garut, Kepala Kelurahan Jayawaras Garut, segenap mahasiswa PPN 38 dan pihak pihak yang sudah membantu kegiatan pengabdian masyarakat. Semoga bantuannya menjadi amal baik dan medapat balasan dari Allah SWT.. Aamiin.

\section{DAFTAR PUSTAKA}

Cahyono, J B Suharjo B. 2008. Gaya Hidup \& Penyakit Modern. Kanisius.

Dahlan, Nurlailah, Muhammad Nadjib Bustan, and Een Kurnaesih. 2018. "Pengaruh Prolanis Terhadap Pengendalian Gula Darah Terkontrol Pada Penderita DM Di Puskesmas Sudiang Kota Makassar.” In Prosiding Seminar Nasional Sinergitas Multidisiplin Ilmu Pengetahuan Dan Teknologi, , 39-49.

Departemen Kesehatan. 2011. "Peraturan Menteri Kesehatan Republik Indonesia Nomor : 2269/MENKES/PER/XI/2011.”

Efendi, Ferry, and Mr Makhfudli. 2010. "Keperawatan Kesehatan Komunitas."

Garut, Dinkes. 2013. "Profil Kesehatan Kabupaten Garut Tahun 2013.” Kabupaten Garut: Dinas Kesehatan Kabupaten Garut.

Hakim, Lukman, and Misna Tazkiah. 2019. "Gambaran Karakteristik Penderita Hipertensi Di Puskesmas Pemurus Baru Banjarmasin.” Kendedes Midwifery Journal 1(3): 34-39.

Junita, Elvira, Yuli Handayani, and Lufita Nur Alfiah. 2020. "GERMAS (Gerakan Masyarakat Hidup Sehat) Di Desa Rambah Hilir.” Kumawula: Jurnal Pengabdian Kepada Masyarakat 3(1): 100-105.

Kartiningrum, Eka Diah, Lembunai Tat Alberta, Dwiharini Puspitaningsih, and Yudha Laga Hadi Kusuma. 2017. 
"Konsep Dasar Keperawatan Komunitas.” E-Book Penerbit STIKes Majapahit: 1-152.

Kemenkes, R I. 2011. "Pedoman Pembinaan Perilaku Hidup Bersih Dan Sehat (PHBS).” Jakarta: Kementerian Kesehatan RI.

- 2013. "Riset Kesehatan Dasar (Riskesdas) 2013.” Kemenkes RI. Jakarta.

2018a. "Laporan Nasional Riskesdas 2018.” Jakarta: Kemenkes RI: 154-66.

2018b. "Profil Kesehatan Indonesia Tahun 2017.” Jakarta: Kementerian Kesehatan RI: 170-73.

Notoatmodjo, Soekidjo. 2014. Promosi Kesehatan Dan Perilkau Kesehatan. Jakarta: Rineka Cipta.

Rosidin, Sumarna, Eriyani. 2019. "Determinan Pelaksanaan PHBS Rumah Tangga Di Desa Jayaraga Tarogong Kidul Kabupaten Garut.” Jurnal Keperawatan BSI 7(1).

Rosidin, Udin, and Iwan Suhendar. 2018. "Penyuluhan Perilaku Hidup Bersih Dan Sehat (PHBS) Tatanan Rumah Tangga Di RW 14 Desa Jayaraga Tarogong Kidul Kabupaten Garut.” Jurnal Kreativitas Pengabdian Kepada Masyarakat (PKM) 1(2).

Setyatama, Ike Putri. 2012. "Hubungan Pengetahuan Dan Motivasi Kader Dengan Peran Kader Posyandu Lansia Di Desa Kangkung Kecamatan Mranggen Kabupaten Demak.” 2(2): 1-7.

Situmorang, Paskah Rina. 2015. "Faktor-faktor Yang Berhubungan Dengan Kejadian Hipertensi Pada Penderita Rawat Inap Di Rumah Sakit Umum Sari Mutiara Medan Tahun 2014.” Jurnal ilmiah keperawatan imelda 1(1): 71-74.

Soenanto, Hardi. 2009. "100 Resep Sembuhkan Hipertensi, Asam Urat, Dan Obesitas.” Jakarta: PT Elex Media Komputindo.
Sumarni, Nina, Udin Rosidin, and Umar Sumarna. 2020. "Penyuluhan Kesehatan Tentang Jajanan Sehat Di Sekolah Dasar Negeri Jati III Tarogong Kaler Garut.” Kumawula: Jurnal Pengabdian Kepada Masyarakat 3(2): 289-97.

Umaroh, Ayu Khoiratul, Heru Yuda Hanggara, and Choiri Choiri. 2016. "Gambaran Perilaku Hidup Bersih Dan Sehat (Phbs) Di Wilayah Kerja Puskesmas Bulu Kabupaten Sukoharjo Bulan JanuariMaret 2015.” Jurnal Kesehatan 9(1): 2531.

Wahidin, Mugi, Annisa Rizky Aprilia, Dwi Susilo, and Sofa Farida. 2019. "Faktor Determinan Hipertensi Pada Pedagang Pasar Cibinong, Jawa Barat.” Media Penelitian dan Pengembangan Kesehatan 29(2): 107-14.

Wahyuningsih, Aries, and Kili Astarani. 2018. "Pendidikan Kesehatan Meningkatkan Pengetahuan, Sikap Dan Ketrampilan Kader Dalam Tatalaksana Anak Sakit ISPA.” Jurnal Penelitian Keperawatan 4(1).

Yarmaliza, Yarmaliza, and Zakiyuddin Zakiyuddin. 2019. "Pencegahan Dini Terhadap Penyakit Tidak Menular (PTM) Melalui GERMAS.” Jurnal Pengabdian Masyarakat Multidisiplin 2(3): 93-100. 